\title{
The microbiome and mosquito vectorial capacity: rich potential for discovery and translation
}

\author{
Cintia Cansado-Utrilla', Serena Y. Zhao ${ }^{2}$, Philip J. McCall ${ }^{3}$, Kerri L. Coon ${ }^{2^{*}}$ and Grant L. Hughes ${ }^{{ }^{*}}$ (D)
}

\begin{abstract}
Microbiome research has gained considerable interest due to the emerging evidence of its impact on human and animal health. As in other animals, the gut-associated microbiota of mosquitoes affect host fitness and other phenotypes. It is now well established that microbes can alter pathogen transmission in mosquitoes, either positively or negatively, and avenues are being explored to exploit microbes for vector control. However, less attention has been paid to how microbiota affect phenotypes that impact vectorial capacity. Several mosquito and pathogen components, such as vector density, biting rate, survival, vector competence, and the pathogen extrinsic incubation period all influence pathogen transmission. Recent studies also indicate that mosquito gut-associated microbes can impact each of these components, and therefore ultimately modulate vectorial capacity. Promisingly, this expands the options available to exploit microbes for vector control by also targeting parameters that affect vectorial capacity. However, there are still many knowledge gaps regarding mosquito-microbe interactions that need to be addressed in order to exploit them efficiently. Here, we review current evidence of impacts of the microbiome on aspects of vectorial capacity, and we highlight likely opportunities for novel vector control strategies and areas where further studies are required.
\end{abstract}

Keywords: Microbiome, Vectorial capacity, Density, Competence, Biting, Extrinsic incubation period, Longevity, Mosquito, Symbiosis, Pathogen transmission

\section{Background}

The 'microbiome' is a collection of microorganisms within or on an organism. In mosquitoes, the microbiome, which consists of bacteria, viruses, protozoans and fungi, profoundly alters host phenotypes. Acquisition and the composition of the microbiome are influenced by several abiotic and biotic factors, including host and microbial genetics [1-4] and the environment [5-7]. Therefore, microbiomes of mosquitoes can vary

\footnotetext{
* Correspondence: kerri.coon@wisc.edu; grant.hughes@lstmed.ac.uk

${ }^{2}$ Department of Bacteriology, University of Wisconsin-Madison, Madison, WI, USA

'Departments of Vector Biology and Tropical Disease Biology, Centre for Neglected Tropical Disease, Liverpool School of Tropical Medicine, Liverpool, UK

Full list of author information is available at the end of the article
}

substantially between individuals, life stages, species and over geographical space $[8,9]$, and this variation likely contributes to differences in host phenotypes [10]. Similarly, the horizontal and vertical transmission routes that microbes exploit to colonise their host mean that mosquitoes reared in a laboratory setting have a vastly different microbiome compared to their field counterparts [11-13]. As such, undertaking studies with a field relevant microbiome has been challenging. Within the mosquito, microbes can invade and colonise different tissues, perhaps by intracellular routes [14], and the reproductive organs $[15,16]$ and salivary glands [17] appear to have the greatest diversity of microbes. Microbiota in the midgut or salivary glands have the potential to interact directly with pathogens whereas

(c) The Author(s). 2021 Open Access This article is licensed under a Creative Commons Attribution 4.0 International License, which permits use, sharing, adaptation, distribution and reproduction in any medium or format, as long as you give appropriate credit to the original author(s) and the source, provide a link to the Creative Commons licence, and indicate if changes were made. The images or other third party material in this article are included in the article's Creative Commons licence, unless indicated otherwise in a credit line to the material. If material is not included in the article's Creative Commons licence and your intended use is not permitted by statutory regulation or exceeds the permitted use, you will need to obtain permission directly from the copyright holder. To view a copy of this licence, visit http://creativecommons.org/licenses/by/4.0/ The Creative Commons Public Domain Dedication waiver (http://creativecommons.org/publicdomain/zero/1.0/) applies to the data made available in this article, unless otherwise stated in a credit line to the data. 
microbes residing in other tissues may indirectly affect vector competence. Microbes that reside in the gut or other tissues $[18,19]$ may also have relevance for other life history traits which influence vectorial capacity.

Vectorial capacity describes the ability of a population of vectors to transmit pathogens to a host and is represented by the vectorial capacity equation (Fig. 1). This was created by Garret-Jones in 1964 and represents the number of secondary cases of vector infection per unit of time given the introduction of an infectious individual into a naïve population [20,21]. Pathogen transmission is modelled by the vectorial capacity equation, which is a vector-centric adaptation of the basic reproductive number $\left(R_{0}\right)$ equation [22]. The components of the vectorial capacity equation are the following: vector biting rate (a), vector density $(\mathrm{m})$, probability of vector daily survival (p), vector competence (b) and pathogen extrinsic incubation period $(\mathrm{N})$. An infected person gets bitten by $m a$ vectors each day. Of these $m a$ bites, only a proportion $b$ is infectious to the vector, giving a total of mab vectors infected by the primary case. The proportion of vectors surviving the extrinsic incubation period is $p^{N}$, so $m a b p^{N}$ vectors become infectious. Each of these infectious vectors then survives for an average time of $1 /$ $-\ln (p)$, and during this time, it bites people at the rate of $a$ bites per day, making a total of $a /-\ln (p)$ bites. Thus, there are $m a b p^{N}$ infectious vectors arising from the primary case making $a /-\ln (p)$ infectious bites on susceptible hosts, resulting in the following vectorial capacity: $m a^{2} b p^{N} /-\ln (p)$. Therefore, each component of the equation will have a certain impact on the ability of mosquitoes to transmit pathogens. As such, targeting any of these components could result in a reduction of pathogen transmission.

Some components of the vectorial capacity equation have traditionally received more attention than others

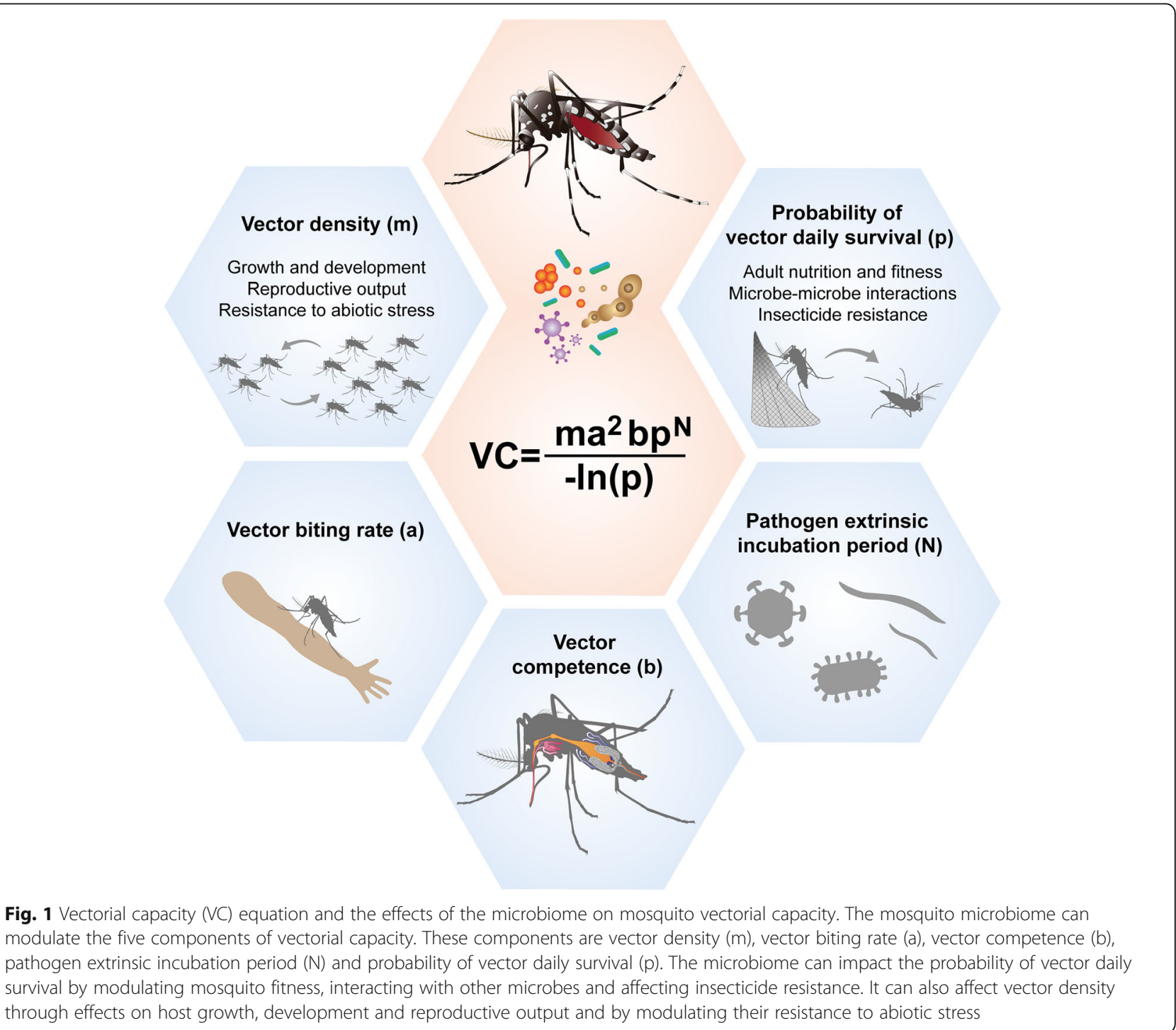


by mosquito control efforts. Probability of daily survival and density have been targeted by adulticides and larvicides respectively, achieving significant reduction of vector-borne diseases, but the emergence of insecticide resistance and diverse non-target effects are compromising these strategies [23]. Vector competence has been the main focus of the design of novel vector control methods, such as release of Wolbachia-infected mosquitoes for population replacement, which has showed unprecedented success in dengue control [24]. However, little attention has been paid to other aspects of mosquito biology which can have equal or potentially greater effect on pathogen transmission [25-28]. In this sense, the great diversity of mosquito gut-associated microbes could offer new tools to target different components of vectorial capacity $[29,30]$. However, in order to leverage the microbiome for vector control, it is imperative to understand how such microbes modulate vector biology. In this review, we compile and consider the evidence of the impact that the mosquito gut-associated microbiome has on particular components of the vectorial capacity equation. We also discuss other vector systems and are guided by what we can infer from other insect models. Finally, we draw from the substantial Wolbachia knowledge base when there is a lack of evidence on how gut-associated microbes influence traits relevant for vectorial capacity in mosquitoes.

\section{Influence of microbiota on vector competence (b)}

All microbes that associate with vectors, including bacteria [31], viruses [32], fungi [33] or microsporidia [34] can modulate vector competence. Vector competence is fundamental to vectorial capacity since it determines the susceptibility of the mosquito to become infected by a pathogen, and the higher the vector competence, the higher the vectorial capacity. Gutassociated microbiota can interfere directly with pathogens through mechanisms such as lysis and biofilm formation [31] or indirectly by affecting intrinsic aspects of the vector that determine its vector competence, like midgut and salivary gland barriers [35-37] and the immune system $[1,38]$. In addition, microbiota can potentially have other functions in pathogen transmission, since it may be transmitted to the mammalian host during feeding on the host [39]. The role of the gut microbiome in modulating vector competence for several pathogens has been well studied and reviewed extensively in mosquitoes [40-47] and other arthropod vectors [48-54], so we have focused our attention on the other components of the vectorial capacity equation.

\section{Influence of microbiota on pathogen extrinsic incubation period $(\mathrm{N})$}

Little is known regarding how microbes influence the extrinsic incubation period (EIP), the time that it takes for pathogens to develop in the vector. This is distinct from vector competence, which concerns the ability of a vector to transmit a pathogen. The EIP affects vectorial capacity since it influences the number of infected mosquitoes that live long enough to become infectious and can vary depending on host and pathogen genetic factors and environmental conditions. There is evidence that Wolbachia infection can extend the EIP for DENV in Aedes aegypti $[55,56]$ and the authors argue that this may be due to the antiviral properties of Wolbachia, which delay the time that the virus titres reach an infectious threshold. Given that gut-associated microbiota modulate pathogens, it would be interesting to explore how the microbiota could be exploited to delay the EIP. Alternatively, microbiota that enhance the EIP could be potentially targeted to prevent a positive effect on pathogen transmission.

\section{Influence of microbiota on vector density ( $m$ )}

Vector density is the number of vectors per host, and there is increasing evidence suggesting that the mosquito gut microbiota can modulate this facet of vectorial capacity. A sustained reduction in vector density leads to progressive population reduction in successive generations, resulting in reduced vectorial capacity. This principle was the cornerstone of many of the earliest vector control strategies, where breeding sites were eliminated or diminished, or treated with larvicides to reduce the number of vectors in a population. It is also the rationale behind more contemporary strategies such as the dissemination of insect growth regulators like pyriproxyfen [57] or the release of Wolbachia-infected male mosquitoes [58, 59]. Gut-associated microbes can influence vector density through the modulation of development, reproductive outputs, and resistance to abiotic stress.

\section{Growth and development}

Recent work has elucidated the importance of microbes as a factor influencing growth and moulting of mosquito larvae into adults by regulating growth signalling and serving as a food source. Axenic (microbe-free) larvae fail to moult under normal environmental conditions [60], and exhibit differential expression of genes relating to amino acid transport, hormone signalling, and metabolism compared to normal larvae [61]. Although some studies have produced larvae that developed without bacteria [62-64], the addition of living microbes appear to induce gut hypoxia and activation of growth-related signalling pathways that larvae require to achieve the critical size necessary for moulting [65-67]. In addition, 
gut hypoxia depends on bacterial density, as shown by Ae. aegypti larvae showing higher growth rates [67] and Aedes albopictus exhibiting enhanced adult emergence [68]. This indicates that the mechanisms responsible for regulation of host development under most conditions occur via microbial metabolism. In the absence of gut hypoxia [66], the larva fails to make adequate nutrient stores, so the mosquito is under microbial influence for accumulation of nutrient reserves that will take it into adulthood. Most mosquito species are detritivorous as larvae, using bacteria and other microorganisms as a food source [69], but predaceous species also consume microorganisms as food when prey are not available, so microbes can contribute to nutritional supply when food availability is a limiting factor [70,71]. Reliance on gut hypoxia for signalling appears to be conserved across mosquito lineages, including detritivorous larvae from the Culicinae and Anophelinae subfamilies, and predaceous larvae of Toxorhynchites amboinensis [72], indicating that the role of larval gut microbiota in mosquito development is not limited to detritivory. Another condition that relies on the nutrients acquired during larval development is autogeny, which is the ability of some mosquito species to produce eggs without blood. Although both anautogenous and autogenous mosquito species rely on the larval microbiota for development, the autogenous Aedes atropalpus display limited rescue of development by some bacterial taxa when reared in monoculture, in contrast to its anautogenous relative $A e$. aegypti [73]. This suggests that autogenous species may have more specific requirements for microbiota composition due to their reliance on larval nutrition and the absence of additional nutrient input from a blood meal. Gut microbes simultaneously regulate signalling and serve as a food source, and further study is required to identify any potential interactions of these dual functions and their impacts on vector life history.

Characterisation of microbiota effects on vector development begins with tracing impacts of individual microbial taxa and continues with the study of bacterial communities and their diversity. Although multiple microbial taxa individually support mosquito development [60], outcomes may differ according to nutrient conditions: Ae. aegypti larvae reared on E. coli, Saccharomyces cerevisiae, or Chlamydomonas reinhardtii, vary in their survival depending on their diet during rearing [67], while Culex pipiens reared on the human pathogen Cryptococcus gattii exhibit reduced larval survival and pupation compared to individuals reared on $S$. cerevisiae or yeasts isolated from wild $C x$. pipiens and $C x$. theileri [74]. Naturally occurring bacterial strains in the genera Klebsiella and Aeromonas are further able to support Cx. pipiens larval development from the first to second instar and are the most attractive to ovipositing females, but fail to produce surviving adults [75]. Particularly impactful microbes may also alter development even when they are not the sole occupant of the larval gut. For example, supplementation of conventionally reared larvae with a culture of Asaia accelerates Anopheles gambiae development; however, it is unknown whether this effect results from Asaia metabolism specifically, or merely from the increased bacterial density [76]. Diversity and community composition of the microbiota also impact development. Larvae reared in the presence of a combination of microbial isolates have higher pupation and survival rates than those reared in monoculture, indicating that a combination of cells of differing nutrient compositions and/or metabolic processes may have additive effects for larval nutrition [77]. In addition, antibiotic treatment, which decreases diversity and abundance of the gut microbiota, delays larval development by $2-4$ days in An. stephensi [78]. However, supplementation of the disturbed microbiota with antibiotic-resistant Asaia restores development, suggesting that the roles of density and diversity in the gut microbiota's modulation of host phenotype is complex and requires further testing.

\section{Reproductive output}

The microbiome can also impact mosquito reproductive output, which is the culmination of several physiological processes and population dynamics. It is influenced by sex ratio and mating behaviour, and results in egg production and hatching. Sex ratio is the number of males or females relative to the total number of emerged adults. The sex ratio of Ae. aegypti was shifted towards a male-biassed sex ratio when larvae were fed with bacteria or yeast [79], although the authors recognised that this could have been due to underfeeding. This may be the result of differences in larval metabolism and development between males and females, so further investigation is needed to understand the mechanisms underpinning this phenotype.

Mating starts with an encounter between individuals, the likelihood of which requires a certain threshold density of a population whose males and females can complete a full coordinated mating behaviour sequence successfully. There is evidence that these traits can be influenced by the gut microbiome. For example, studies in Drosophila indicate that larvae congregate in response to acetoin produced by the gut microbiome [80], leading to an increase in adult density over time. The absence of a gut microbiota in contrast leads to hyperactive adult behaviour [81] that is normalized by the addition of Lactobacillus, which produces enzymes that influence neuronal pathways involved in locomotion [81]. Some mosquitoes mate in swarms, and variation in microbiota between swarms has also been observed [82], although further work is required to determine the cause and 
functional implications of these differences. After making an initial encounter a potential mate must have its identity and suitability as a fit mate confirmed before mating begins. In Drosophila, a greater number of matings were observed when males and females were reared on diets containing the same microbial consortia as opposed to diets with different microbial communities [83, 84]. Microbe-mediated changes in the levels or composition of sex pheromones and other mating cues could be responsible for this phenotype [85]. First, the production of hydrocarbons is regulated by the insulin signalling pathway, which is enhanced by Wolbachia in Drosophila [86]. Second, changes in the ratios of cuticular hydrocarbons affect mating recognition and sexual attractiveness of these and other flies [87-89]. Further investigation is required in order to disentangle the effects of the microbiota on host mating behaviour since this could affect genetic control strategies in vectors. For example, transgenic mosquitoes with enhanced immunity also have a modified microbiome and a mating fitness advantage compared to their wild type counterparts [90], potentially by microbiome-induced alterations of cuticular hydrocarbons. This resulted in wild-type male mosquitoes preferentially mating with genetically modified females and genetically modified males having a preference for wild-type females, thereby spreading the genetic modification into the population [90].

In addition to effects on sex ratio and mating behavior, egg production, oviposition, and hatching in insects are all affected by microbiota, and this impact on fecundity translates to changes in vector density. In general, fecundity in mosquitoes is governed by nutrients acquired during blood feeding, so blood digestion by adult females is necessary for egg production. A significant increase of microbe levels occurs after mosquitoes take a bloodmeal [91-93], and treatment of Ae. aegypti with antibiotics impedes digestion of blood proteins and consequently reduces egg production [94], suggesting that the microbiome contributes to blood digestion. Recently, it has been shown that sequential bloodmeals promote pathogen infection $[95,96]$, and it would be intriguing to determine the role of the microbiome in this phenotype. Recent studies also indicate that Ae. aegypti eggs laid in water containing bacteria hatch at a higher rate than those laid in sterile water [97] and female mosquitoes from many species preferentially oviposit in microbe-rich water [98]. Allelochemicals associated with bacteria have been identified [99], but the mosquito response can vary dramatically depending on its previous exposure to a particular chemical $[100,101]$. Taking together, it is evident that gut microbes enhance mosquito fecundity and therefore the mechanisms that facilitate these phenotypes could be targeted to reduce vector density. As opposed to gut microbes, some Wolbachia strains seem to reduce female fecundity, egg hatch, and quiescent egg viability $[102,103]$, which results in a reduction of vector density and therefore vectorial capacity.

\section{Resistance to abiotic stress}

Some vector species can survive (or are adapted to live) under adverse conditions, such as low humidity, brackish water or competitive environments, which permits colonisation of a broader range of environments. Resistance of mosquito eggs to desiccation is variable among species, and three main factors drive this variability: chitin content, egg volume and shell density [104]. Evidence that gut-associated microbiota regulate two enzymes involved in chitin synthesis (GFAT and CHS2) in An. gambiae [37] suggests the potential for the microbiome to influence resistance to desiccation. Once eggs have hatched, larvae have to persist in their aquatic environment. Whilst most mosquito species breed in fresh water, Culex sitiens and An. sundaicus survive in brackish water [105]. In general, the microbiome can confer resistance to salinity in plants and animals [106, 107], suggesting similar advantages could be conferred by gutassociated microbes to their mosquito hosts. Mosquito larvae in natural environments also occur within food webs that include both interspecific and intraspecific competitors and predators. The influence of the microbiome on larval competition is still to be determined, but Wolbachia infection has been shown to cause a density-dependent effect on larval survival [108]. Microbes that protect mosquitoes against abiotic stresses would be good candidates for paratransgenesis as this trait would likely facilitate their spread and persistence in the mosquito population.

\section{Influence of microbiota on probability of vector daily survival ( $p$ )}

The probability of daily survival is the chance that a vector survives each day, and pathogens with longer EIPs may be particularly sensitive to this parameter. The microbiome has the potential to affect survival by altering adult nutrition and fitness, interacting with other microbes, and modulating insecticide resistance.

\section{Adult nutrition and fitness}

The microbiome can impact insect survival by affecting host fitness, nutrition, homeostasis, and metabolism of their host. One indicator of mosquito fitness (among many others) is body size, and in general microbiota enhance development and size of mosquitoes. For example, An. gambiae and An. stephensi supplemented with Asaia have shown increased growth rates [76]. Similarly, when An. coluzzi mosquitoes were reared on three distinct diets, larger mosquitoes where seen to harbour a greater 
bacterial load [109]. Mosquito larvae fed solely with either bacteria or yeast still developed, although were smaller than their counterparts fed on food sources [79], suggesting that microbes alone provide some sustenance for the insect. Smaller mosquitoes are more susceptible to environmental stressors and thus have a reduced chance of survival [110]; therefore, microbe stimulation of nutrition can influence vector population dynamics.

Adult mosquitoes obtain their nutrients from two food sources, sugar and blood, and the microbiome plays an important role in food digestion and nutrient provision. Enterobacteriaceae is the most active family of the gut microbiota of Ae. albopictus at assimilating fructose, a major sugar component of nectar [111] and this sugar is used by bacteria as an energy source to produce other nutrients for the mosquito host. The impact of gutassociated microbiota on nutrition has also been studied in model insects, and results in these systems could shed insights into mechanisms occurring in mosquitoes. Examples include complementation of vitamins missing from the diet in other hematophagous insects [112] and Drosophila [113], and alteration of expression of genes involved in energy storage in Riptortus pedestris [114].

In Ae. aegypti [115] and An. arabiensis [116], disturbance of gut homeostasis resulted in a shortened lifespan, so inducing microbiome dysbiosis in vectors may be explored as a novel control strategy. There is precedent for microbial-based life-shortening approaches, with modelling and empirical evidence suggesting some strains of Wolbachia can reduce pathogen transmission due to their effects on longevity [117-119] and density [120]. However, this strategy was not pursued after it became apparent that Wolbachia interfered with pathogen development in the vector, and hence, population replacement could be undertaken by that route instead. Microbiome-mediated alterations in metabolites in the host can also lead to different survival outcomes. A recent study demonstrated that bacteria which lowered methionine content of food extended Drosophila host lifespan [121]. Although this was tested in flies, methionine has been shown to act as a larvicide against several mosquito species such as An. quadrimaculatus, Ae. albopictus and $C x$. tarsalis [122], suggesting that similar processes could occur in mosquitoes. Another study in Drosophila showed that the production of lithocholic acid by the adult gut microbiota elongated host survival through upregulation of genes involved in glucose homeostasis [123], offering a potential target in the host to shorten lifespan. The insulin growth factor signalling pathway is central to regulation of lifespan [124-126], and can be impacted by bacterial metabolism in mosquitoes [66], although the mechanisms are unknown.

Host-microbe symbioses are complex and are influenced by host physiology, microbial composition and the timing of infection. The lifespan of An. coluzzii is extended with exposure to doxycycline but shortened with azithromycin [127], suggesting that changes in microbiome composition are driving this phenotype, although direct effects from the antibiotic need to be considered. Similarly, axenically reared or antibiotic-treated Drosophila had reduced lifespans, but if flies were exposed to bacteria in their first week as adults, their lifespan was similar to their conventionally reared counterparts [128]. In contrast, a study that compared axenic D. melanogaster with gnotobiotic flies infected with Acetobacter pomorum found no differences in survival. However, axenic flies had greater glucose levels and lower oxygen consumption, suggesting a potential overall slowing of respiration [129]. These findings indicate that host changes associated with microbiota may manifest as intermediate phenotypes rather than detectable changes in lifespan and thus studies that measure overall fitness outcomes may miss subtle effects of the microbiota. Further work is needed to identify which affected host functions impact longevity, and whether similar longevity phenotypes may obscure other trait differences. Hostmicrobe interactions become even more complex when some members of the microbiome shift from a commensal to a pathogen status and vice versa [130]. This can happen due to temperature, presence of pathogens, and other unknown factors $[131,132]$. Such transitions of status and the broad range of possible complexities of host-microbe interactions should not be ignored when considering basic research questions and ultimately when considering microbiome control strategies.

\section{Microbe-microbe interactions}

The diverse microbes that reside within insects may interact with pathogens that are detrimental to the host, making the vector either more resistant, tolerant, or susceptible to infection and thus impacting lifespan. For example, Rickettsia, an endosymbiont of whiteflies, reduces the density of pathogenic Pseudomonas resulting in an extended lifespan for its host [133]. In contrast, the infection of mosquitoes with the pathogenic fungus Beauveria bassiana causes microbiome dysbiosis and over-proliferation and translocation of Serratia marcescens from the gut to the hemocoel, eventually killing the insect [134]. Microbes can benefit from each other, like symbiotic bacteria and yeast in Drosophila [135], but they can also exclude one another, like Enterobacteriaceae and Serratia [136] or Asaia and Wolbachia [137] in mosquitoes. In flies and mosquitoes, microbiota interactions with Wolbachia occur but these do not influence the ability of Wolbachia to block pathogens [138, 139]. However in general, these complex microbial interactions determine microbiome composition and colonisation of the host [11, 140], influencing host physiology 
and lifespan [141] and therefore the effectiveness of microbial control of mosquitoes [142].

\section{Insecticide resistance}

Gut-associated microbiota may also indirectly affect mosquito lifespan by mediating resistance to insecticides. Evidence is emerging that mosquitoes with differing resistance status have distinct microbiomes [143, 144], but further work is required to investigate the causality and the mechanisms underpinning these associations. Streptococcus, Pseudomonas, Klebsiella, and Pantoea correlated with insecticide resistance in An. arabiensis [145], An. albimanus [146, 147] and An. stephensi [148]. Wolbachia has also been associated with insecticide resistance in Culex pipiens [149]. Detoxifying symbionts in the gut microbiome have been shown to confer insecticide resistance in other insects like wasps [150], honeybees [151] and insect pests [152]. Although the mechanisms have not been described in mosquitoes, the ability of some of these bacteria to degrade insecticides [146] provides a possible explanation. Additionally, bacteria present in the soil may become resistant to insecticides due to chronic exposure [153] and these bacteria may colonise insects, either transiently or stably. A more complete understanding of the role of the microbiome on insecticide resistance will enable the development of strategies to mitigate the emergence of resistance and extend the longevity of currently used formulations.

\section{Influence of microbiota on vector biting rate (a)}

Vector biting rate is the average number of times that a vector bites per unit of time and can be modulated by the microbiome by impacting feeding behaviour and host preference. An increased biting rate leads to a higher vectorial capacity, since the vector has more opportunities to acquire and transmit pathogens. Feeding behaviour is disrupted in Ae. aegypti by Serratia [136] and in Anopheles mosquitoes when exposed to heatkilled E. coli [154] or Chromobacterium [155]. Microbiota also have the potential to affect host-seeking behaviour through modulation of their chemosensory system. In D. melanogaster, symbionts determine larval pheromone preference [80] and affect the adult olfactory system, influencing food choice [156-158]. Additionally, gut bacteria are known to modulate expression levels of vitellogenin genes in the true bug, Riptortus pedestris [114], and in Ae. albopictus, vitellogenin expression regulates host-seeking behaviour [159]. Therefore, the ability of the microbiome to impact host seeking behaviour, possibly through modulation of vitellogenesis, should be further investigated.

\section{Conclusions}

There is emerging evidence that the microbiome of vectors can influence many traits important for vectorial capacity. At the same time, many studies highlight the complexities of microbial communities and variability of the microbiome in mosquitoes. Attempts to disentangle this complexity often examine the effect of a specific microbe on the host, such as those that exploit monoaxenic gnotobiotic infections; however, it is unclear if these findings translate to mosquitoes with a complete microbiome consisting of many microbes. Additionally, applied strategies need to be effective in hosts with divergent microbiomes which mosquitoes possess in the field so understanding microbial interactions is integral. Other challenges for the scientific community to solve include moving beyond simple descriptions of the microbiome of distinct mosquito cohorts or mosquitoes with differing treatments to validating the microbes or microbial consortia that are the causal agents of host phenotypes, and the eventual elucidation of the mechanisms responsible for those interactions. Much can be learned from other research areas where the complexity of microbial community composition is also a challenge [160-164]. Advances in omics technologies can be used to disentangle this complexity, but this can also be addressed by grouping microorganisms with common life history and interspecific relationships [165], which can then be linked to effects on the host and then vectorial capacity. Ultimately, the development of sustainable strategies to modulate vectorial capacity by introducing microbes into wild mosquito populations will require a thorough understanding of microbiome acquisition and the factors controlling its composition and abundance. Only then can the full potential of the microbiome for vector control be realised.

\section{Acknowledgements \\ GLH was supported by the BBSRC (BB/T001240/1 and BB/N011278/1), a Royal Society Wolfson Fellowship (RSWF\R1 180013), NIH grants (R21Al124452 and R21Al129507), the UKRI (20197 and 85336), the EPSRC (V043911/1) and the NIHR (NIHR2000907). GLH is affiliated to the National Institute for Health Research Health Protection Research Unit (NIHR HPRU) in Emerging and Zoonotic Infections at University of Liverpool in partnership with Public Health England (PHE), in collaboration with Liverpool School of Tropical Medicine and the University of Oxford. GLH is based at LSTM. The views expressed are those of the authors and not necessarily those of the NHS, the $\mathrm{NIHR}$, the Department of Health or Public Health England. CCU was \\ supported by the Medical Research Council (N013514/1) and the Liverpool School of Tropical Medicine. KLC was supported by the NSF (2019368), USDA NIFA (2018-67012-29991), and the University of Wisconsin-Madison. SYZ was supported by the NSF (Graduate Research Fellowship 1747503) and NIH (T32Al007414). PJM receives support from the Bill \& Melinda Gates Founda- tion (BMGF OPP1159078 and OPP1200155) and from BBSRC/MRC UK (MR/ T001267/1).}

\section{Authors' contributions}

CCU and SYZ performed the literature review and wrote the manuscript. GLH and KLC assisted in reviewing literature and provided critical and intellectual input to the manuscript. PJM provided useful comments and edits on the manuscript. All authors read and approved the final manuscript. 
Availability of data and materials

Not applicable

\section{Declarations}

Ethics approval and consent to participate

Not applicable

\section{Consent for publication}

Not applicable

\section{Competing interests}

The authors declare that they have no competing interests.

\section{Author details}

${ }^{1}$ Departments of Vector Biology and Tropical Disease Biology, Centre for Neglected Tropical Disease, Liverpool School of Tropical Medicine, Liverpool, UK. ${ }^{2}$ Department of Bacteriology, University of Wisconsin-Madison, Madison, WI, USA. ${ }^{3}$ Department of Vector Biology, Liverpool School of Tropical Medicine, Liverpool, UK.

\section{Received: 9 January 2021 Accepted: 7 April 2021}

\section{Published online: 18 May 2021}

\section{References}

1. Stathopoulos S, Neafsey DE, Lawniczak MKN, Muskavitch MAT, Christophides GK. Genetic dissection of Anopheles gambiae gut epithelial responses to Serratia marcescens. PLoS Pathog. 2014;10:1003897.

2. Hamidou I, Berthier D, Tchicaya B, Thevenon S, Njiokou F, Cuny G, et al. Infection, genetics and evolution population dynamics of Glossina palpalis gambiensis symbionts, Sodalis glossinidius, and Wigglesworthia glossinidia throughout host-fly development. Infect Genet Evol. 2013;13:41-8.

3. Rocha David M, Barbosa dos Santos LM, Paulo Vicente AC, Maciel-de-Freitas $R$. Effects of environment, dietary regime and ageing on the dengue vector microbiota: evidence of a core microbiota throughout Aedes aegypti lifespan. Mem Inst Oswaldo Cruz. 2016;111:577-587, 9, DOI: https://doi.org/1 0.1590/0074-02760160238.

4. Hegde S, Nilyanimit P, Kozlova E, Anderson ER, Narra HP, Sahni SK, et al. CRISPR/Cas9-mediated gene deletion of the ompA gene in symbiotic Cedecea neteri impairs biofilm formation and reduces gut colonization of Aedes aegypti mosquitoes. PLoS Negl Trop Dis. 2019;13:7883.

5. Corbin C, Jones JE, Chrostek E, Fenton A, Hurst GDD. Thermal sensitivity of the Spiroplasma-Drosophila hydei protective symbiosis: the best of climes, the worst of climes. Mol Ecol. 2021;30(5):1336-44. https://doi.org/10.1111/ mec.15799.

6. Kešnerová L, Emery O, Troilo M, Liberti J, Erkosar B, Engel P. Gut microbiota structure differs between honeybees in winter and summer. ISME J. 2019;14: 801-14

7. Onyango GM, Bialosuknia SM, Payne AF, Nicholas M, Ciota AT, Kramer LD. Increase in temperature enriches heat tolerant taxa in Aedes aegypti midguts. Sci Rep. 2020;10(1):19135. https://doi.org/10.1038/s41598-020-761 88-x.

8. Muturi EJ, Lagos-kutz D, Dunlap C, Ramirez JL, Rooney AP, Hartman GL, et al. Mosquito microbiota cluster by host sampling location. Parasit Vectors. 2018;11:468.

9. Novakova E, Woodhams DC, Rodríguez-ruano SM. Mosquito microbiome dynamics, a background for prevalence and seasonality of West Nile virus. Front Microbiol. 2017:8:526.

10. Dickson LB, Jiolle D, Minard G, Moltini-Conclois I, Volant S, Ghozlane A, et al. Carryover effects of larval exposure to different environmental bacteria drive adult trait variation in a mosquito vector. Sci Adv. 2017;3:585.

11. Hegde S, Khanipov K, Albayrak L, Golovko G, Pimenova M, Saldaña MA, et al. Microbiome interaction networks and community structure from laboratory-reared and field-collected Aedes aegypti, Aedes albopictus, and Culex quinquefasciatus mosquito vectors. Front Microbiol. 2018:9:2160.

12. Saab SA, Dohna H, Nilsson LKJ, Onorati P, Nakhleh J, Tereni O, et al. The environment and species affect gut bacteria composition in mosquitoes. Sci Rep. 2020;10(1):3352. https://doi.org/10.1038/s41598-020-60075-6.

13. Dada N, Benedict AC, Lol JC, Sheth M, Dzuris N, Padilla N, et al. Geographic heterogeneity in Anopheles albimanus microbiota is lost within one generation of laboratory colonization. bioRxiv. 2020;2020.06.02.129619. https://doi.org/10.1101/2020.06.02.129619.

14. Hegde S, Voronin D, Casas-Sanchez A, Saldaña MA, Heinz E, Acosta-Serrano A, et al. Gut-associated bacteria invade the midgut epithelium of Aedes aegypti and stimulate innate immunity and suppress Zika virus infection in cells. bioRxiv. 2020:866897.https://doi.org/10.1101/866897.

15. Juma EO, Kim CH, Dunlap C, Allan BF, Stone CM. Culex pipiens and Culex restuans egg rafts harbor diverse bacterial communities compared to their midgut tissues. Parasites Vectors. 2020;13:532.

16. Mancini MV, Damiani C, Accoti A, Tallarita M, Nunzi E, Cappelli A, et al. Estimating bacteria diversity in different organs of nine species of mosquito by next generation sequencing. BMC Microbiol. 2018;18(1):126. https://doi. org/10.1186/s12866-018-1266-9.

17. Sharma P, Sharma S, Maurya RK, Das DT, Thomas T, Lata S, et al. Salivary glands harbor more diverse microbial communities than gut in Anopheles culicifacies. Parasites Vectors. 2014;7:235

18. Tchioffo MT, Boissière A, Abate L, Nsango SE, Bayibéki AN, Awono-Ambéné $\mathrm{PH}$, et al. Dynamics of bacterial community composition in the malaria mosquito's epithelia. Front Microbiol. 2016:6:1500.

19. Chavshin AR, Oshaghi MA, Vatandoost H, Yakhchali B, Zarenejad F, Terenius O. Malpighian tubules are important determinants of Pseudomonas transstadial transmission and longtime persistence in Anopheles stephensi. Parasites Vectors. 2015:8:36

20. Garret-Jones. The prognosis for interruption of malaria transmission through assessment of the mosquito's vectorial capacity. Nature. 1964;204:1173-5.

21. Garrett-Jones C, Grab B. The assessment of insecticidal impact on the malaria mosquito's vectorial capacity, from data on the proportion of parous females. WHO. 1964:31:71-86.

22. MacDonald G. The epidemiology and control of malaria. London: Oxford University Press; 1957.

23. Moyes CL, Vontas J, Martins AJ, Ng LC, Koou SY, Dusfour I, et al. Contemporary status of insecticide resistance in the major Aedes vectors of arboviruses infecting humans. PLoS Negl Trop Dis. 2017;11:5625.

24. Indriani C, Tantowijoyo W, Rancès E, Andari B, Prabowo E, Yusdi D, et al. Reduced dengue incidence following deployments of Wolbachia-infected Aedes aegypti in Yogyakarta, Indonesia: a quasi-experimental trial using controlled interrupted time series analysis. Gates Open Res. 2020;4:50.

25. Carvajal-Lago L, Ruiz-López MJ, Figuerola J, Martínez-de la Puente J. Implications of diet on mosquito life history traits and pathogen transmission. Environ Res. 2021;195:110893.

26. Smith DL, McKenzie FE. Statics and dynamics of malaria infection in Anopheles mosquitoes. Malar J. 2004;3(1):13. https://doi.org/10.1186/1475-2 875-3-13.

27. Sherrard-Smith E, Skarp JE, Beale AD, Fornadel C, Norris LC, Moore SJ, et al. Mosquito feeding behavior and how it influences residual malaria transmission across Africa. Proc Natl Acad Sci U S A. 2019;116(30):15086-95. https://doi.org/10.1073/pnas.1820646116.

28. Kiware SS, Chitnis N, Moore SJ, Devine GJ, Majambere S, Merrill S, et al. Simplified models of vector control impact upon malaria transmission by zoophagic mosquitoes. PLoS One. 2012;7:37661

29. Shane JL, Grogan CL, Cwalina C, Lampe DJ. Blood meal-induced inhibition of vector-borne disease by transgenic microbiota. Nat Commun. 2018;9(1): 4127. https://doi.org/10.1038/s41467-018-06580-9.

30. Saldaña MA, Hegde S, Hughes GL. Microbial control of arthropod-borne disease. Mem Inst Oswaldo Cruz. 2017:112:81-93.

31. Castro DP, Seabra SH, Garcia ES, de Souza W, Azambuja P. Trypanosoma cruzi: ultrastructural studies of adhesion, lysis and biofilm formation by Serratia marcescens. Exp Parasitol. 2007;117(2):201-7. https://doi.org/10.101 6/j.exppara.2007.04.014.

32. Patterson El, Villinger J, Muthoni JN, Dobel-Ober L, Hughes GL. Exploiting insect-specific viruses as a novel strategy to control vector-borne disease. Curr Opin Insect Sci. 2020;39:50-6. https://doi.org/10.1016/j.cois.2020.02.005.

33. Angleró-Rodríguez Yl, Talyuli OAC, Blumberg BJ, Kang S, Demby C, Shields A, et al. An Aedes aegypti-associated fungus increases susceptibility to dengue virus by modulating gut trypsin activity. Elife. 2017;6:28844.

34. Herren JK, Mbaisi L, Mararo E, Makhulu EE, Mobegi VA, Butungi H, et al. A microsporidian impairs Plasmodium falciparum transmission in Anopheles arabiensis mosquitoes. Nat Commun. 2020:11:2187.

35. Franz AWE, Kantor AM, Passarelli AL, Clem RJ. Tissue barriers to arbovirus infection in mosquitoes. Viruses. 2015:7:3741-67. 
36. Song X, Wang M, Dong L, Zhu H, Wang J. PGRP-LD mediates A. stephensi vector competency by regulating homeostasis of microbiota-induced peritrophic matrix synthesis. PLOS Pathog. 2018;14:1006899.

37. Rodgers FH, Gendrin M, Wyer CAS, Christophides GK. Microbiota-induced peritrophic matrix regulates midgut homeostasis and prevents systemic infection of malaria vector mosquitoes. PLoS Pathog. 2017;13:1006391.

38. Eleftherianos L, Atri J, Accetta J, Castillo JC. Endosymbiotic bacteria in insects: guardians of the immune system? Front Physiol. 2013;4:46.

39. Dey $R$, Joshi AB, Oliveira F, Pereira $L$, Guimarães-Costa AB, Serafim $T D$, et al. Gut microbes egested during bites of infected sand flies augment severity of leishmaniasis via inflammasome-derived IL-1ß. Cell Host Microbe. 2018;23: 134-43.

40. Romoli $\mathrm{O}$, Gendrin M. The tripartite interactions between the mosquito, its microbiota and Plasmodium. Parasites and Vectors. Parasites Vectors. 2018; 11(1):200. https://doi.org/10.1186/s13071-018-2784-x.

41. Hegde S, Rasgon JL, Hughes GL. The microbiome modulates arbovirus transmission in mosquitoes. Curr Opin Virol. 2015:15:97-102.

42. Souza-Neto JA, Powell JR, Bonizzoni M. Aedes aegypti vector competence studies: a review. Infect Genet Evol. 2019;67:191-209. https://doi.org/10.10 6/j.meegid.2018.11.009

43. Dennison NJ, Jupatanakul N, Dimopoulos G. The mosquito microbiota influences vector competence for human pathogens. Curr Opin Insect Sci. 2014;3:6-13.

44. Caragata EP, Tikhe CV, Dimopoulos G. Curious entanglements: interactions between mosquitoes, their microbiota, and arboviruses. Curr Opin Virol. 2019:37:26-36.

45. Gao H, Cui C, Wang L, Jacobs-Lorena M, Wang S. Mosquito microbiota and implications for disease control. Trends Parasitol. 2020;36:98-111.

46. Scolari F, Casiraghi M, Bonizzoni M. Aedes spp. and their microbiota: a review. Front Microbiol. 2019;10:2036.

47. Yin C, Sun P, Yu X, Wang P, Cheng G. Roles of symbiotic microorganisms in arboviral infection of arthropod vectors. Trends Parasitol. 2020;36(7):607-15. https://doi.org/10.1016/j.pt.2020.04.009.

48. Cirimotich CM, Ramirez JL, Dimopoulos G. Native microbiota shape insect vector competence for human pathogens. Cell Host Microbe. 2011;10:307-10.

49. Farikou O, Njiokou F, Mbida JA, Njitchouang GR, Geiger A, Nana H, et al. Tripartite interactions between tsetse flies, Sodalis glossinidius and trypanosomes - an epidemiological approach in two historical human African trypanosomiasis foci in Cameroon. Infect Genet Evol. 2010;10:11521.

50. Telleria EL, Martins-Da-Silva A, Tempone AJ, Traub-Cseko YM. Leishmania, microbiota and sand fly immunity. Parasitology. 2018;145(10):1336-53. https://doi.org/10.1017/S0031182018001014

51. Weiss B, Aksoy S. Microbiome influences on insect host vector competence. Trends Parasitol. 2011:27:514-22.

52. Bonnet SI, Binetruy F, Hernández-Jarguín AM, Duron O. The tick microbiome: why non-pathogenic microorganisms matter in tick biology and pathogen transmission. Front Cell Infect Microbiol. 2017;7:236.

53. Möhlmann TWR, Vogels CBF, Göertz GP, Pijlman GP, ter Braak CJF, te Beest $D E$, et al. Impact of gut bacteria on the infection and transmission of pathogenic arboviruses by biting midges and mosquitoes. Microb Ecol. Microbial Ecology. 2020;80:703-17.

54. Jupatanakul N, Sim S, Dimopoulos G. The insect microbiome modulates vector competence for arboviruses. Viruses. 2014;6(11):4294-313. https://doi. org/10.3390/v6114294

55. Carrington LB, Tran BCN, Le NTH, Luong TTH, Nguyen TT, Nguyen PT, et al. Field- and clinically derived estimates of Wolbachia-mediated blocking of dengue virus transmission potential in Aedes aegypti mosquitoes. Proc Natl Acad Sci U S A. 2017;115:361-6.

56. Ye YH, Carrasco AM, Frentiu FD, Chenoweth SF, Beebe NW, van den Hurk $A F$, et al. Wolbachia reduces the transmission potential of dengue-infected Aedes aegypti. PLoS Negl Trop Dis. 2015:9:3894.

57. Hustedt JC, Boyce R, Bradley J, Hii J, Alexander N. Use of pyriproxyfen in control of aedes mosquitoes: a systematic review. PLoS Negl Trop Dis. 2020; 14:e0008205.

58. Zheng $X$, Zhang D, Li Y, Yang C, Wu Y, Liang $X$, et al. Incompatible and sterile insect techniques combined eliminate mosquitoes. Nature. 2019;572:56-61.

59. Crawford JE, Clarke DW, Criswell V, Desnoyer M, Cornel D, Deegan B, et al. Efficient production of male Wolbachia-infected Aedes aegypti mosquitoes enables large-scale suppression of wild populations. Nat Biotechnol. 2020; 38(4):482-92. https://doi.org/10.1038/s41587-020-0471-x.
60. Coon KL, Vogel KJ, Brown MR, Strand MR. Mosquitoes rely on their gut microbiota for development. Mol Ecol. 2014;23(11):2727-39. https://doi. org/10.1111/mec.12771.

61. Vogel KJ, Valzania L, Coon KL, Brown MR, Strand MR. Transcriptome sequencing reveals large-scale changes in axenic Aedes aegypti larvae. PLoS Negl Trop Dis. 2017;11:5273.

62. Correa MA, Matusovsky B, Brackney DE, Steven B. Generation of axenic Aedes aegypti demonstrate live bacteria are not required for mosquito development. Nat Commun. 2018;9(1):4464. https://doi.org/10.1038/s41467018-07014-2.

63. Munderloh UG, Kurtti TJ, Maramorosch K. Anopheles stephensi and Toxorhynchites amboinensis: aseptic rearing of mosquito larvae on cultured cells. J Parasitol. 1982:68:1085-91.

64. Romoli O, Schönbeck JC, Hapfelmeier S, Gendrin M. Bacteria contribute to mosquito development via folate biosynthesis and energy storage.Nat Commun. 2021;12:942

65. Coon KL, Valzania L, Mckinney DA, Vogel KJ, Brown MR, Strand MR. Bacteriamediated hypoxia functions as a signal for mosquito development. PNAS. 2017:114:5362-9.

66. Valzania L, Coon KL, Vogel KJ, Brown MR, Strand MR. Hypoxia-induced transcription factor signaling is essential for larval growth of the mosquito Aedes aegypti. PNAS. 2018;115:457-65.

67. Valzania L, Martinson VG, Harrison RE, Boyd BM, Coon KL, Brown R, et al. Both living bacteria and eukaryotes in the mosquito gut promote growth of larvae. PLoS Negl Trop Dis. 2018;12:6638.

68. Wang X, Liu T, Wu Y, Zhong D, Zhou G, Su X, et al. Bacterial microbiota assemblage in Aedes albopictus mosquitoes and its impacts on larval development. Mol Ecol. 2018;27:2972-85.

69. Timmermann SE, Briegel H. Effect of plant, fungal and animal diets on mosquito development. Entomol Exp Appl. 1996;80:173-6.

70. Washburn JO. Regulatory factors affecting larval mosquito populations in container and pool habitats: implications for biological control. J Am Mosq Control Assoc. 1995;11:279-83.

71. Barrera R, Amador M, Clark GG. Ecological factors influencing Aedes aegypti (Diptera: Culicidae) productivity in artificial containers in Salinas, Puerto Rico. J Med Entomol. 2006:43:484-92.

72. Coon KL, Valzania L, Brown MR, Strand MR. Predaceous Toxorhynchites mosquitoes require a living gut microbiota to develop. Proc $\mathrm{R}$ Soc B Biol Sci. 2020;287:20192705

73. Coon KL, Brown MR, Strand MR. Gut bacteria differentially affect egg production in the anautogenous mosquito Aedes aegypti and facultatively autogenous mosquito Aedes atropalpus (Diptera: Culicidae). Parasit Vectors. Parasites Vectors. 2016;9:375

74. Steyn A, Roets F, Botha A. Yeasts associated with Culex pipiens and Culex theileri mosquito larvae and the effect of selected yeast strains on the ontogeny of Culex pipiens. Microb Ecol. 2016;71(3):747-60. https://doi.org/1 0.1007/s00248-015-0709-1.

75. Díaz-Nieto LM, D’Alessio C, Perotti MA, Berón CM. Culex pipiens development is greatly influenced by native bacteria and exogenous yeast. PLoS One. 2016;11:153133

76. Mitraka E, Stathopoulos S, Siden-Kiamos I, Christophides GK, Louis C. Asaia accelerates larval development of Anopheles gambiae. Pathog Glob Health. 2013;107:305-11.

77. Travanty NV, Apperson CS, Ponnusamy L. A diverse microbial community supports larval development and survivorship of the Asian tiger mosquito (Diptera: Culicidae). J Med Entomol. 2019;56:632-40.

78. Chouaia B, Rossi P, Epis S, Mosca M, Ricci I, Damiani C, et al. Delayed larval development in Anopheles mosquitoes deprived of Asaia bacterial symbionts. BMC Microbiol. 2012;12(Suppl 1):S2. https://doi.org/10.1186/14 71-2180-12-S1-S2

79. Santos Souza R, Virginio F, Souza Riback TI, Suesdek L, Bonomi Barufi J, Arie GF. Microorganism-based larval diets affect mosquito development, size and nutritional reserves in the Yellow Fever mosquito Aedes aegypti (Diptera: Culicidae). Front Physiol. 2019;10:152.

80. Farine JP, Habbachi W, Cortot J, Roche S, Ferveur JF. Maternally-transmitted microbiota affects odor emission and preference in Drosophila larva. Sci Rep. 2017;7:6062.

81. Schretter CE, Vielmetter J, Bartos I, Marka Z, Marka S, Argade S, et al. A gut microbial factor modulates locomotor behaviour in Drosophila. Nature. 2018:563(7731):402-6. https://doi.org/10.1038/s41586-018-0634-9. 
82. Segata N, Baldini F, Pompon J, Garrett WS, Truong DT, Dabiré RK, et al. The reproductive tracts of two malaria vectors are populated by a core microbiome and by gender-and swarm-enriched microbial biomarkers. Sci Rep. 2016;6:24207.

83. Sharon G, Segal D, Ringo JM, Hefetz A, Zilber-Rosenberg I, Rosenberg E. Commensal bacteria play a role in mating preference of Drosophila melanogaster. PNAS. 2010;107:20051-6.

84. Sharon G, Segal D, Zilber-Rosenberg I, Rosenberg E. Symbiotic bacteria are responsible for diet-induced mating preference in Drosophila melanogaster, providing support for the hologenome concept of evolution. Gut Microbes. 2011;2:190-2.

85. Davis TS, Crippen TL, Hofstetter RW, Tomberlin JK. Microbial volatile emissions as insect semiochemicals. J Chem Ecol. 2013;39:840-59.

86. Ikeya T, Broughton S, Alic N, Grandison R, Partridge L. The endosymbiont Wolbachia increases insulin/IGF-like signalling in Drosophila. Proc R Soc B Biol Sci. 2009;276(1674):3799-807. https://doi.org/10.1098/rspb.2009.0778.

87. Snellings $Y$, Herrera B, Wildemann B, Beelen M, Zwarts L, Wenseleers T, et al. The role of cuticular hydrocarbons in mate recognition in Drosophila suzukii. Sci Rep. 2018;8:4996.

88. Kuo TH, Fedina TY, Hansen I, Dreisewerd K, Dierick HA, Yew JY, et al. Insulin signaling mediates sexual attractiveness in Drosophila. PLoS Genet. 2012;8: 1002684.

89. Engl T, Michalkova V, Weiss BL, Uzel GD, Takac P, Miller WJ, et al. Effect of antibiotic treatment and gamma-irradiation on cuticular hydrocarbon profiles and mate choice in tsetse flies (Glossina m. morsitans). BMC Microbiol. 2018;18:145

90. Pike A, Dong Y, Dizaji NB, Gacita A, Mongodin EF, Dimopoulos G. Changes in the microbiota cause genetically modified Anopheles to spread in a population. Science. 2017;357:1396-9.

91. Gusmão DS, Santos AV, Marini DC, Bacci M, Berbert-Molina MA, Lemos FJA. Culture-dependent and culture-independent characterization of microorganisms associated with Aedes aegypti (Diptera: Culicidae) (L.) and dynamics of bacterial colonization in the midgut. Acta Trop. 2010;115:275-81.

92. Muturi EJ, Dunlap C, Ramirez JL, Rooney P, Kim C. Host blood-meal source has a strong impact on gut microbiota of Aedes aegypti. FEMS Microbiol Ecol. 2019;95:1.

93. Oliveira JHM, Gonçalves RLS, Lara FA, Dias FA, Gandara ACP, Menna-Barreto RFS, et al. Blood meal-derived heme decreases ROS levels in the midgut of Aedes aegypti and allows proliferation of intestinal microbiota. PLoS Pathog. 2011;7:1001320.

94. Gaio ADO, Gusmão DS, Santos AV, Berbert-molina MA, Pimenta PFP, Lemos FJA. Contribution of midgut bacteria to blood digestion and egg production in aedes aegypti (Diptera: Culicidae) (L .). Parasit Vectors. 2011;4: 105.

95. Armstrong PM, Ehrlich HY, Magalhaes T, Miller MR, Conway PJ, Bransfield A, et al. Successive blood meals enhance virus dissemination within mosquitoes and increase transmission potential. Nat Microbiol. 2020;5:239-47.

96. Serafim TD, Coutinho-Abreu IV, Oliveira F, Meneses C, Kamhawi S, Valenzuela JG. Sequential blood meals promote Leishmania replication and reverse metacyclogenesis augmenting vector infectivity. Nat Microbiol. 2018;3:548-55

97. Ponnusamy L, Böröczky K, Wesson DM, Schal C, Apperson CS. Bacteria stimulate hatching of yellow fever mosquito eggs. PLoS One. 2011;6:24409.

98. McCall PJ. Chemoecology of oviposition in bloodfeeding and carnivorous insects. In: Meiners T, Hilker M, editors. Chemoecology of insect eggs and egg deposition; 2002. p. 265-89.

99. Ponnusamy L, Xu N, Nojima S, Wesson DM, Schal C, Apperson CS. Identification of bacteria and bacteria-associated chemical cues that mediate oviposition site preferences by Aedes aegypti. Proc Natl Acad Sci U S A. 2008;105:9262-7.

100. Vinauger C, Lahondère C, Cohuet A, Lazzari CR, Riffell JA. Learning and memory in disease vector insects. Trends Parasitol. 2016;32(10):761-71. https://doi.org/10.1016/j.pt.2016.06.003.

101. Mccall PJ, Eaton G. Olfactory memory in the mosquito Culex quinquefasciatus. Med Vet Entomol. 2001;15:197-203.

102. Yeap HL, Mee P, Walker T, Weeks AR, O'Neill SL, Johnson P, et al. Dynamics of the "popcorn" Wolbachia infection in outbred Aedes aegypti informs prospects for mosquito vector control. Genetics. 2011;187:583-95.

103. Ant TH, Herd CS, Geoghegan V, Hoffmann AA, Sinkins P. The Wolbachia strain wAu provides highly efficient virus transmission blocking in Aedes aegypti. PLoS Pathog. 2018;14:1006815.
104. Farnesi LC, Menna-Barreto RFS, Martins AJ, Valle D, Rezende GL. Physical features and chitin content of eggs from the mosquito vectors Aedes aegypti, Anopheles aquasalis and Culex quinquefasciatus: connection with distinct levels of resistance to desiccation. J Insect Physiol. 2015;83:43-52. https://doi.org/10.1016/j.jinsphys.2015.10.006.

105. Dusfour I, Harbach RE, Manguin S. Bionomics and systematics of the oriental Anopheles sundaicus complex in relation to malaria transmission and vector control. Am J Trop Med Hyg. 2004;71:518-24.

106. Yuan Z, Druzhinina IS, Labbé J, Redman R, Qin Y, Rodriguez R, et al. Specialized microbiome of a halophyte and its role in helping non-host plants to withstand salinity. Sci Rep. 2016;6:32467.

107. Röthig T, Ochsenkühn MA, Roik A, Van Der Merwe R, Voolstra CR. Long-term salinity tolerance is accompanied by major restructuring of the coral bacterial microbiome. Mol Ecol. 2016;25:1308-23.

108. Gavotte L, Mercer DR, Stoeckle JJ, Dobson SL. Costs and benefits of Wolbachia infection in immature Aedes albopictus depend upon sex and competition level. J Invertebr Pathol. 2010;105:341-6.

109. Linenberg I, Christophides GK, Gendrin M. Larval diet affects mosquito development and permissiveness to Plasmodium infection. Sci Rep. 2016; 6(1):38230. https://doi.org/10.1038/srep38230.

110. Barreaux AMG, Stone CM, Barreaux P, Koella JC. The relationship between size and longevity of the malaria vector Anopheles gambiae (s.s.) depends on the larval environment. Parasites and Vectors. Parasites Vectors. 2018;11:485.

111. Guégan M, Tran Van V, Martin E, Minard G, Tran F-H, Fel B, et al. Who is eating fructose within the Aedes albopictus gut microbiota? Environ Microbiol. 2020;22:1193-1206.

112. Rio RVM, Attardo GM, Weiss BL. Grandeur alliances: symbiont metabolic integration and obligate arthropod hematophagy. Trends Parasitol. 2016;32: 739-49.

113. Sannino DR, Dobson AJ, Edwards K, Angert ER, Buchon N. The Drosophila melanogaster gut microbiota provisions thiamine to its host. MBio. 2018;9: 00155-18.

114. Lee JB, Park KE, Lee SA, Jang SH, Eo HJ, Jang HA, et al. Gut symbiotic bacteria stimulate insect growth and egg production by modulating hexamerin and vitellogenin gene expression. Dev Comp Immunol. 2017;69:12-22.

115. Nunes RD, Ventura-Martins G, Moretti DM, Medeiros-Castro P, Rocha-Santos C, Daumas-Filho CR de O, et al. Polyphenol-rich diets exacerbate AMPKmediated autophagy, decreasing proliferation of mosquito midgut microbiota, and extending vector lifespan. PLoS Negl Trop Dis. 2016;10: 5034.

116. Debalke S, Habtewold T, Duchateau L, Christophides GK. The effect of silencing immunity related genes on longevity in a naturally occurring Anopheles arabiensis mosquito population from southwest Ethiopia. Parasites Vectors. 2019;12:174.

117. Brownstein JS, Hett E, O'Neill SL. The potential of virulent Wolbachia to modulate disease transmission by insects. J Invertebr Pathol. 2003:84:24-9.

118. Rasgon JL, Styer LM, Scott TW. Wolbachia-induced mortality as a mechanism to modulate pathogen transmission by vector arthropods. J Med Entomol. 2003:40:125-32.

119. McMeniman CJ, Lane RV, Cass BN, Fong AWC, Sidhu M, Wang YF, et al. Stable introduction of a life-shortening Wolbachia infection into the mosquito Aedes aegypti. Science. 2009;323:141-4.

120. Nazni WA, Hoffmann AA, NoorAfizah A, Cheong YL, Mancini MV, Golding N, et al. Establishment of Wolbachia strain wAlbB in Malaysian populations of Aedes aegypti for dengue control. Curr Biol. 2019;29:4241-8.

121. Matthews MK, Wilcox H, Hughes R, Veloz M, Hammer A, Banks B, et al. Genetic influences of the microbiota on Drosophila melanogaster lifespan. Appl Environ Microbiol. 2020;86:305-20.

122. Weeks ENI, Baniszewski J, Gezan SA, Allan SA, Cuda JP, Stevens BR. Methionine as a safe and effective novel biorational mosquito larvicide. Pest Manag Sci. 2019;75(2):346-55. https://doi.org/10.1002/ps.5118.

123. Staats S, Rimbach G, Kuenstner A, Graspeuntner S, Rupp J, Busch H, et al. Lithocholic acid improves the survival of Drosophila melanogaster. Mol Nutr Food Res. 2018;62:1800424.

124. Tatar M, Kopelman A, Epstein D, Tu MP, Yin CM, Garofalo RS. A mutant Drosophila insulin receptor homolog that extends life-span and impairs neuroendocrine function. Science. 2001;292(5514):107-10. https://doi.org/1 $0.1126 /$ science. 1057987.

125. Giannakou ME, Goss M, Jünger MA, Hafen E, Leevers SJ, Partridge L. Longlived Drosophila with over-expressed dFOXO in adult fat body. Science. 2004;305(5682):361. https://doi.org/10.1126/science.1098219. 
126. Arik AJ, Hun LV, Quicke K, Piatt M, Ziegler R, Scaraffia PY, et al. Increased Akt signaling in the mosquito fat body increases adult survivorship. FASEB J. 2015;29:1404-13.

127. Gendrin M, Yerbanga RS, Ouedraogo JB, Lefèvre T, Cohuet A, Christophides GK. Differential effects of azithromycin, doxycycline, and cotrimoxazole in ingested blood on the vectorial capacity of malaria mosquitoes. Open Forum Infect Dis. 2016;3:ofw074.

128. Brummel T, Ching A, Seroude L, Simon AF, Benzer S. Drosophila lifespan enhancement by exogenous bacteria. Proc Natl Acad Sci U S A. 2004; 101(35):12974-9. https://doi.org/10.1073/pnas.0405207101.

129. Ridley EV, Wong ACN, Westmiller S, Douglas AE. Impact of the resident microbiota on the nutritional phenotype of Drosophila melanogaster. PLoS One. 2012;7:36765.

130. Kim E, Lee K, Hyeon DY, Kyung M, Jun K, Seo SH, et al. Bacterial nucleoside catabolism controls quorum sensing and commensal-to-pathogen transition in the Drosophila gut. Cell Host Microbe. 2020;27:345-57.

131. Seitz HM, Maier WA, Rottok M, Becker-Feldmann H. Concomitant infections of anopheles stephensi with plasmodium berghei and serratia marcescens: additive detrimental effects. Zentralblatt fur Bakteriol Mikrobiol und Hyg. 1987;266:155-66.

132. Liu X-D, Lei H-X, Chen F-F. Infection pattern and negative effects of a facultative endosymbiont on its insect host are environment-dependent. Sci Rep. 2019;9:4013.

133. Hendry TA, Hunter MS, Baltrus A. The facultative symbiont Rickettsia protects an invasive whitefly against entomopathogenic Pseudomonas syringae strains. Appl Environ Microbiol. 2014;80:7161-8.

134. Wei G, Lai Y, Wang G, Chen H, Li F, Wang S. Insect pathogenic fungus interacts with the gut microbiota to accelerate mosquito mortality. PNAS. 2017:114:5994-9.

135. Guilhot R, Rombaut A, Howell K, Fellous S, Supagro M, Sciences A. Bacterial influence on the maintenance of symbiotic yeast through Drosophila metamorphosis. bioRxiv. 2020. https://doi.org/10.1101/2020.05.31.126185.

136. Kozlova EV, Hegde S, Roundy CM, Golovko G, Saldaña MA, Hart CE, et al. Microbial interactions in the mosquito gut determine Serratia colonization and blood-feeding propensity. ISME J. 2021;15(1):93-108. https://doi.org/1 0.1038/s41396-020-00763-3.

137. Rossi P, Ricci I, Cappelli A, Damiani C, Ulissi U, Mancini MV, et al. Mutual exclusion of Asaia and Wolbachia in the reproductive organs of mosquito vectors. Parasit Vectors. 2015;8:278.

138. Ye YH, Seleznev A, Flores HA, Woolfit M, McGraw EA. Gut microbiota in Drosophila melanogaster interacts with Wolbachia but does not contribute to Wolbachia-mediated antiviral protection. J Invertebr Pathol. 2017;143:1825. https://doi.org/10.1016/j.jip.2016.11.011.

139. Audsley MD, Ye YH, McGraw EA. The microbiome composition of Aedes aegypti is not critical for Wolbachia-mediated inhibition of dengue virus. PLoS Negl Trop Dis. 2017;11:0005426.

140. Hughes GL, Dodson BL, Johnson RM, Murdock CC, Tsujimoto H, Suzuki Y, et al. Native microbiome impedes vertical transmission of Wolbachia in Anopheles mosquitoes. Proc Natl Acad Sci U S A. 2014;111:12498-503.

141. Gould AL, Zhang V, Lamberti L, Jones EW, Obadia B, Korasidis N. Microbiome interactions shape host fitness. PNAS. 2018;115:11951-60.

142. Dacey DP, Chain FJJ. The challenges of microbial control of mosquito-borne diseases due to the gut microbiome. Front Genet. 2020;11:504354.

143. Omoke D, Kipsum M, Otieno S, Esalimba E, Sheth M, Lenhart A, et al. Western Kenyan Anopheles gambiae showing intense permethrin resistance harbour distinct microbiota. Malar J. 2021;20:77.

144. Arévalo-Cortés A, Mejia-Jaramillo AM, Granada Y, Coatsworth H, Lowenberger C, Triana-Chavez O. The midgut microbiota of Colombian Aedes aegypti populations with different levels of resistance to the insecticide lambda-cyhalothrin. Insects. 2020;11:584.

145. Barnard K, Jeanrenaud ACSN, Brooke BD, Oliver SV. The contribution of gut bacteria to insecticide resistance and the life histories of the major malaria vector Anopheles arabiensis (Diptera: Culicidae). Sci Rep. 2019;9:9117.

146. Dada N, Sheth M, Liebman K, Pinto J, Lenhart A. Whole metagenome sequencing reveals links between mosquito microbiota and insecticide resistance in malaria vectors. Sci Rep. 2018;8(1):2084. https://doi.org/10.1038/ s41598-018-20367-4.

147. Dada N, Lol JC, Benedict AC, López F, Sheth M, Dzuris N, et al. Pyrethroid exposure alters internal and cuticle surface bacterial communities in Anopheles albimanus. ISME J. 2019;13:2447-64.
148. Soltani A, Vatandoost H, Oshaghi MA, Enayati AA, Chavshin AR. The role of midgut symbiotic bacteria in resistance of Anopheles stephensi (Diptera: Culicidae) to organophosphate insecticides. Pathog Glob Health. 2017;11: 289-96.

149. Berticat C, Rousset F, Raymond M, Berthomieu A, Weill M. High Wolbachia density in insecticide-resistant mosquitoes. Proc R Soc B Biol Sci. 2002; 269(1498):1413-6. https://doi.org/10.1098/rspb.2002.2022.

150. Wang GH, Berdy BM, Velasquez O, Jovanovic N, Alkhalifa S, Minbiole KPC, et al. Changes in microbiome confer multigenerational host resistance after sub-toxic pesticide exposure. Cell Host Microbe. 2020;27:213-24.

151. Motta EVS, Raymann K, Moran NA. Glyphosate perturbs the gut microbiota of honey bees. PNAS. 2018;115(41):10305-10. https://doi.org/10.1073/pnas.1 803880115.

152. Van Den Bosch TJM, Welte CU. Detoxifying symbionts in agriculturally important pest insects. Microb Biotechnol. 2017;10(3):531-40. https://doi. org/10.1111/1751-7915.12483.

153. Rangasamy K, Athiappan M, Devarajan N, Parray JA. Emergence of multi drug resistance among soil bacteria exposing to insecticides. Microb Pathog. 2017;105:153-65.

154. Cator LJ, George J, Blanford S, Murdock CC, Baker TC, Read AF, et al. "Manipulation" without the parasite: altered feeding behaviour of mosquitoes is not dependent on infection with malaria parasites. Proc $\mathrm{R}$ Soc B Biol Sci. 2013;280:20130711.

155. Gnambani EJ, Bilgo E, Sanou A, Dabiré RK, Diabaté A. Infection of highly insecticide-resistant malaria vector Anopheles coluzzii with entomopathogenic bacteria Chromobacterium violaceum reduces its survival, blood feeding propensity and fecundity. Malar J. 2020;19:352.

156. Fischer C, Trautman EP, Crawford JM, Stabb EV, Handelsman J, Broderick NA. Metabolite exchange between microbiome members produces compounds that influence Drosophila behavior. Elife. 2017;6:18855.

157. Wong ACN, Wang QP, Morimoto J, Senior AM, Lihoreau M, Neely GG, et al. Gut microbiota modifies olfactory-guided microbial preferences and foraging decisions in Drosophila. Curr Biol. 2017;27:2397-404.

158. Leitão-Gonçalves R, Carvalho-Santos Z, Francisco AP, Fioreze GT, Anjos M, Baltazar C, et al. Commensal bacteria and essential amino acids control food choice behavior and reproduction. PLoS Biol. 2017;15:2000862.

159. Dittmer J, Alafndi A, Gabrieli P. Fat body-specific vitellogenin expression regulates host-seeking behaviour in the mosquito Aedes albopictus. PLoS Biol. 2019;17:3000238.

160. Fierer N. Embracing the unknown: disentangling the complexities of the soil microbiome. Nat Rev Microbiol. 2017;15:579-90.

161. Goodrich JK, Davenport ER, Clark AG, Ley RE. The relationship between the human genome and microbiome comes into view. Annu Rev Genet. 2017; 51(1):413-33. https://doi.org/10.1146/annurev-genet-110711-155532.

162. Bulgarelli D, Rott M, Schlaeppi K, Ver Loren van Themaat E, Ahmadinejad N, Assenza F, et al. Revealing structure and assembly cues for Arabidopsis rootinhabiting bacterial microbiota. Nature. 2012;488:91-5.

163. Pachiadaki MG, Brown JM, Brown J, Bezuidt O, Berube PM, Biller SJ, et al. Charting the complexity of the marine microbiome through single-cell genomics. Cell. 2019;179(7):1623-35. https://doi.org/10.1016/j.cell.2019.11.017.

164. Anantharaman K, Brown CT, Hug LA, Sharon I, Castelle CJ, Probst AJ, et al. Thousands of microbial genomes shed light on interconnected biogeochemical processes in an aquifer system. Nat Commun. 2016;7:13219.

165. Krause S, Le Roux X, Niklaus PA, van Bodegom PM, Lennon JT, Bertilsson S, et al. Trait-based approaches for understanding microbial biodiversity and ecosystem functioning. Front Microbiol. 2014;5:251.

\section{Publisher's Note}

Springer Nature remains neutral with regard to jurisdictional claims in published maps and institutional affiliations. 